\title{
Autonomy of educated urban women and their attitude towards female foeticide in India
}

\section{Dweepika Kumari}

\author{
Patna University, India
}

The Sex-ratio in India is continuously declining in spite of gradually increasing literacy among women. For long, it was thought that illiteracy and female subjugation is the reason why women are unable to stand for their rights. As such, large scale attempts and programs had been taken to increase the literacy of women. But in spite of the spread of female education and increasing women autonomy in Urban India, the female foeticide has continued to increase. Most of the results in the recent reports suggest that child sex ratio is inversely linked to female literacy and female economic activity rate, especially in urban India. Thus, this study is an attempt to prove that simply increasing the female literacy and autonomy without bringing about the change in mind-set will not be completely successful in combating the problem of female foeticide. It explores the level of autonomy being enjoyed by the Women of Patna, their attitude towards female foeticide and also the factors which arouse the son-preference in them.

Key Words: Women autonomy, Education, Empowerment, Female Foeticide, D.M. Index.

Article Info: Received: January 24, 2014; Revised: December 12, 2014; Accepted: March 15, 2015; Online: April 24, 2015.

\section{Introduction}

The Indian society like most of the East and South Asian countries is patriarchal to such an extent that even the birth of a girl child in a family is sought to be avoided. Earlier female infants were killed immediately after her birth using various means. However, with increasing technology and the introduction of sex determination tests like sonography, amniocentesis or ultrasound etc. female child is being eliminated in the womb itself. This practice known as female foeticide has become so rampant in India that it has led to a decline in the ratio between the number of men and women in the total population.

\section{Correspondence address}

Address: Dweepika Kumari, Department of Geography, Patna University, C/o. D.P. Singh, Lane no. 2, Vijayanagar, Rukunpura, Bailey Road, Patna -14, Bihar, India.

Phone: +91-8083625256 | Email: dweepika09@gmail.com 
The sex-ratio has declined from 972 females per 1000 males in 1901 to 940 females in 2011. Though the overall sex-ratio has shown a little improvement during the past two decades, the child sex-ratio (number of girls per 1000 boys) has continued its declining trend to reach an abysmal low of 914. Various social, economic and demographic indicators provide evidence of a gender bias as well as deep rooted prejudice and discrimination against women and girl child. Though there are several factors which are individually and collectively responsible for declining sex-ratio in India, the women's role is also very vital for understanding the current increase in the proportion of male versus female.

The Sex-ratio in India is continuously declining in spite of gradually increasing literacy among women. For long, it was thought that illiteracy is the reason why people fail to understand the importance of women and the consequence of rapidly declining sex-ratio and that the female subjugation is the reason why women are unable to stand for their rights and against atrocities on themselves. But paradoxically, as revealed by the decennial censuses held in India, in spite of the spread of female education and increasing women autonomy, especially in Urban India, the strong preference for sons and the consequent elimination of the girl child has continued to increase. This trend has been further boosted by the progress in science and technology, as the techniques for the elimination of the girl child have become scientific. Female infanticide has now been replaced by female foeticide. Clearly, any moral guilt that might remotely be attached to the elimination of the girl child after she is born does not exist if she is eliminated while still in the womb. Also, any emotional attachment that a mother might develop during the period of pregnancy towards her unborn child also ceases to exist.

The educated Indian women of today are very conscious of begetting only one or two issues, but in quite a number of cases, they also want to make sure that they have at least one son to perpetuate their family and family traditions. Unlike, the traditional son-preferring women, most of whom were God-fearing, and did not prefer killing their daughters considering it as a sin, these significant proportion of the modern educated women adopt their own so called „rational and logical thinking. According to quite a number of these educated women, sex-selective abortion is a better way of family planning as through this they can plan both, the number and the gender composition of their offspring.

In the light of the above facts the author in this study has selected Patna Municipal Corporation as the study area and chosen those women, as the study sample, who are both educated and autonomous (i.e. enjoy good decision making power in their day to day life). The word 'Educated' in this article does not just mean literate (i.e. able to read and write) but rather those who have completed at least their Graduation level education. The author aims to first assess the attitude of these Educated and Autonomous women towards female foeticide i.e. whether they justify female foeticide or not and then to analyse the factors which instigate them towards female foeticide.

\section{Relation between female literacy and sex ratio in India}

It is a common perception among people that the sex-selective abortion is more rampant among the illiterate people especially women and especially in the rural 
Table 1. Sex Ratio at Birth by Level of Education of the Mother

\begin{tabular}{lcccccc}
\hline & Illiterate & $\begin{array}{c}\text { Education } \\
\text { below } \\
\text { Primary } \\
\text { level }\end{array}$ & $\begin{array}{c}\text { Primary but } \\
\text { below } \\
\text { Matric }\end{array}$ & $\begin{array}{c}\text { Middle but } \\
\text { below Matric }\end{array}$ & $\begin{array}{c}\text { Below } \\
\text { Graduation }\end{array}$ & $\begin{array}{c}\text { Graduate } \\
\text { and above }\end{array}$ \\
\hline INDIA & 920 & 909 & 894 & 885 & 867 & 876 \\
BIHAR & 930 & 902 & 887 & 873 & 850 & 846 \\
\hline
\end{tabular}

Source - Annual report 2006 on implementation of the pre-Conception and Pre-natal Techniques (PNDT) prohibition of sex selection Act (2005), PNDT Division, Ministry of Health and Family welfare, GOI, New Delhi,

Note: Based on births during the last year presented in 2001 Census Table F-11

areas. (It is an observation by the author during the talks with the respondents for primary level survey and not based on any secondary data). Urban people especially those with higher education often consider themselves as modern and free from traditional mind-set of son-preference. But this is not so in reality.

According to Census of India 2011, there is much variation in the pattern of both the sex ratio and the female literacy. Sex ratio is not necessarily high in the states having higher female literacy rate e.g. Delhi, Punjab, Haryana, Gujarat, Maharashtra, West Bengal, Sikkim and Nagaland. Similarly, the states with low female literacy do not necessarily have lower sex ratio e.g. Andhra Pradesh. Likewise, very often urban people state that the inhuman practice of sex-selective abortions is more rampant in the rural areas. However, there are some states where the level of urbanization is quite high but the sex ratio is dismally poor. On the contrary, few states like Odisha and Meghalaya have very low level of urbanization. Still, their sex-ratio is much better compared to the rest of the nation.

Table 1 clearly shows a surprising inverse relation between the education level of the mothers and the sex ratio at birth. According to the annual report 2006 of the implementation of PC and PNDT Act, the sex ratio at birth shows a general declining trend with the rise in the level of education of the mother.

This study is an extension of the doctorate thesis of the author (extension because it is based on the data collected for the doctorate thesis of the author. It is not a part of the actual thesis). The study is based on an exhaustive primary level survey conducted by the author.

\section{Methodology}

The methodology of research work for the present study follows three distinct phases:

Pre-Field survey - The pre-field survey involves the review of the concerned literature, reconnaissance survey of the study area and collection of the base map of Patna Municipal Corporation, Bihar, India.

Field Survey and Sample selection - Preparation of the questionnaire, collection of the primary data by applying Stratified Random Sampling covering 1040 samples. The total population of Patna, according to the census of India 2001, is 14.32 lakhs of which 6.50 lakhs are women. Out of the total female population a significant number were not eligible to be included in this sample. Unmarried girls up to the age of 20 have not been included as this survey requires the women to have a 

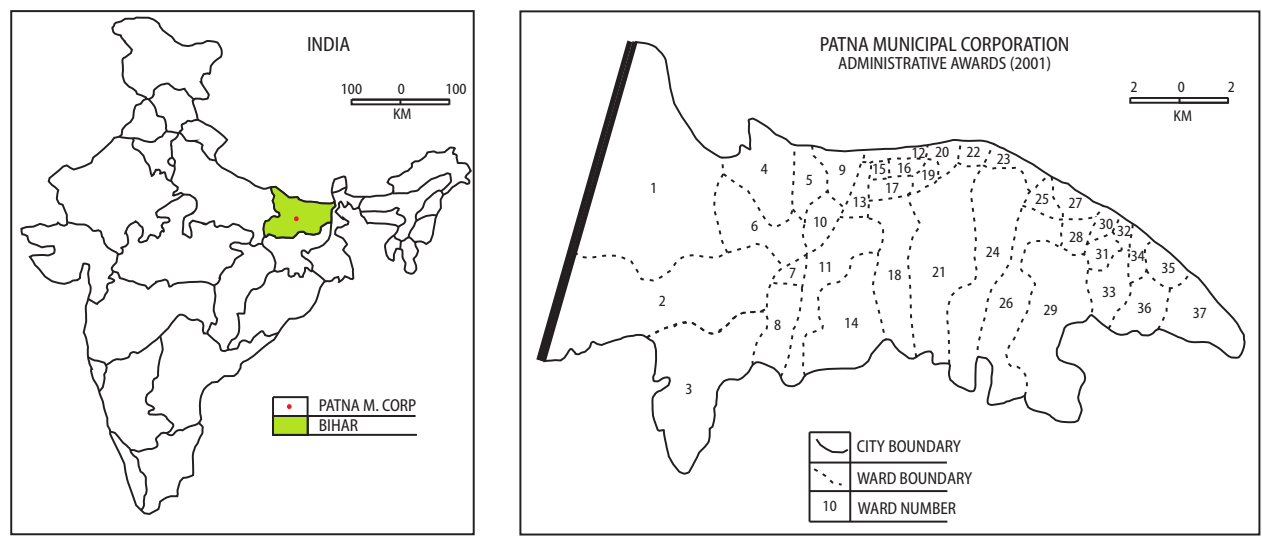

Figure 1. Location of study area (Patna Municipal Corporation) in Bihar, India

mature understanding of the social setup and especially about marital life and the prevailing views on son preference. As such, among the women below 20 years, only the married ones were selected for the sample. The very old women who would have been unable to comprehend the questionnaire were also excluded from the sample.

The original study attempted at analyzing the behavioral mindset of the women with respect to the prevailing attitude of son-preference and daughter discrimination. The study required a comprehensive study so that the views are not biased or one- sided. As such it was ensured that the sample of selected women cuts across different age groups (25 years and below - 13\%, 2655-76\%, above 55 years $11 \%$ ), economic class (Poor - 17\%, Middle class $-75 \%$, Rich $-8 \%$ ), educational (Illiterate- 17\%, Matriculate - 33\%, Graduate - 26\%, Post- Graduate - 13\%) and socio- religious background. Thus, the sample of the respondents selected for the survey is such that the results present a picture for the entire female population in the study area as a whole.

Post-Field Survey - While the original respondent sample was collected with a holistic approach towards view of women towards son preference and female foeticide, this particular study focuses on the "Educated Autonomous women" and their attitude towards female foeticide, therefore out of the total sample size, the number of women having both higher education (i.e. graduate or higher degree) and having a moderate to high autonomy had to be sorted out.

For this purpose, a decision-making index was developed which has been used to find out the level of autonomy of women. Thereafter, the women having both higher education and moderate to high autonomy were selected for further study. The post-field survey stage involved the tabulation and analysis of primary data, use of statistical techniques and cartographic representation, development of suitable index for data assessment and finally the analysis of the data.

\section{Decision-making index: A tool for assesing the level of Women Autonomy}

Specifically in case of women, the term "Autonomy" has been variously defined as: 
"The ability ... to maintain information and use it as the basis for making decisions about one's private concerns and those of one's intimates" (Dyson and Moore, 1983).

“The degree of women's access to and control over material resources (including food, income, land and other forms of wealth) and to social resources (including knowledge, power and prestige) within the family, in the community and the society at large" (Dixon, 1978).

"The control women have over their lives- the extent to which they have an equal voice with their husbands in matters affecting themselves and their families, control over material and other resources, access to knowledge and information, the authority to make independent decisions, freedom from constraints on physical mobility and the ability to forge equitable power relationships within families" (Jejeebhoy, 2001).

The literature related to women autonomy and empowerment suggests several separate but interdependent components to autonomy. These include the decision making autonomy; physical autonomy; emotional autonomy; knowledge autonomy and economic autonomy (see, for example, Mason 1984; Caldwell 1979; Caldwell, Reddy, and Caldwell 1982; Jejeebhoy 1995).

\section{Method for calculation of Decision-Making Index}

A Decision-making (D.M) Index has been developed by the author which reflects the level of autonomy of the respondents surveyed. This D.M. Index is the sum of weightage (or points) accorded to the women depending upon their level of participation in different categories of household decision-making matters. A strategy of subjective proportionate weightage technique has been adopted here according to the significance level perceived by the scholar herself during the survey keeping in view the social system and the prevailing norms. Four categories of decision-making matters have been chosen and Proportionate weightage has been given to the individual aspect depending upon their importance level. The aspects which have greater impact on the autonomy of women, e.g. the number and timing of children or her mobility have been given higher weightage while general or day to day matters like cooking of food etc., which have less significance, have been given lesser weightage.

Number and timing of children - As this decision gives a woman a control over her own body, this aspect is of paramount importance, it has been given the highest weightage i.e., 6 points. This decision if taken in mutual understanding with the husband which reflects cordial mutual relationship is given 4 points. In some cases a woman also accepts her husband's wishes even if she does not desire the same, simply to maintain their cordial relation. Thus in such cases 3 points are given. However, when this decision is influenced by others (in-laws etc.) and is forced to undergo several pregnancies against her wishes she loses all her reproductive rights and so only 1 point is given.

Visit to friends and relatives - This decision relates to freedom of mobility. This freedom of mobility allows a woman to come out of the confines of the four walls of her house into the contact with the outer world, broadens her mental horizons and gives her confidence. As this aspect also deals with the contact with her friends and 
natal kin which boosts her autonomy, the self-decision-making rights of a woman and thus is given 6 points. Mutual decision of husband and wife in this regard is granted 4 points. This decision when taken by others, though indicates restriction on a woman's freedom but is also a reflection of our cultural tradition where the elder's permission is considered necessary and thus is given 2 points.

Major household purchases - Purchasing of household items is a matter of household issues. Having a control over these decisions reflects their greater participation and active role in the household affairs and thus economic decisionmaking autonomy. Mutual decision-making in this regard is given 4 points. In case this decision is taken by others i.e. the in-laws, this reflects that the elders in the family are in control of the financial matters and that the women at a later age has a greater chance of gaining more economic autonomy and thus is given 3 points. The husband being the sole decision-maker in this regard indicates total lack of participation by women and is given 2 points.

Food to be cooked - The kitchen from time immemorial has been considered as the traditional arena of women and cooking as the sole responsibility of women, therefore decision regarding this has been left entirely to them. Thus this is not a significant indicator of the autonomy of the women and hence the woman has been given 4 points if they are the sole decision-makers in this regard, 3 points in case of mutual decisions. Sometimes she also cooks according to the wishes of the family members; consequently 2 points are given in this condition. However if the food is cooked solely according to the husbands wish or choice with her negligible participation then she is given only 1 point.

Later the weightage points of individual respondents in the four categories were summed up to find out the Decision-Making Index (D. M. INDEX). The points given to different respondents in different categories varies according to their level of autonomy in that particular category. Similar measures have been used by several authors (for e.g. Jejeebhoy 2001; Mason et al. 1995; Kishor 2000). The decision-making index or D. M. INDEX is thus, calculated on the basis of the different weightage given to the different variables. The highest weightage accorded to any respondent in the case where she was able to take the decision on her own ranges from 4 to 6 depending upon the relative importance of that variable and the lowest weightage was 1 to 3 . Thus, the decisionmaking index ranges from 8 to 21 . The level of decision-making autonomy of each respondent was fixed according to decision-making index.

Of the total 1040 women selected during the initial sample survey, 65 respondents were unmarried and economically dependent on their parents so autonomy assessment was not applicable on them and 21 respondents chose not to answer this section. So the assessment of autonomy and calculation of Decisionmaking Index was done only for 954 women. Out of the total 954 women who were covered for this particular analysis, 212 (22\%) enjoyed high level of autonomy, $258(27 \%)$ were moderately autonomous, 273(29\%) were less autonomous while $211(22 \%)$ had a very less autonomy.

\section{Decision-Making Autonomy of women according to their education}

When the level of decision-making autonomy of women of Patna was analysed according to the educational level of the respondents the influence of education on 
the level of autonomy became quite obvious. Of all the illiterate women $24 \%$ and about $29 \%$ of the non-matric women have very less autonomy. However, $26 \%-28 \%$ of the women in this educational group also enjoy high autonomy. This is because these women are also the senior most in age group and exercise influence on account of their position in family.

However, when we compare the remaining four literacy groups i.e. Matric, Intermediate, graduates and Post-graduates, a greater percentage of women of the lesser literacy group are in very less decision-making autonomy category i.e. (20$25 \%$ ) compared to only $16-18 \%$ of the higher literacy groups. One more feature which is quite striking is that the percentage of women having high autonomy decreases with increasing education i.e. $28 \%$ of the illiterate women, $26 \%$ of nonmetric's, $21 \%$ of matriculates, $17 \%$ of intermediates, $19 \%$ of graduates and $17 \%$ of the Post-graduates. This is because in case of less education either women are unable to assert their authority at all or by the virtue of their age and position in family they command a total control over their family. Many of them are also financially independent and thus are assertive of their decisions. While with increasing education, the women gain confidence and assertiveness. However, in such cases the couples have a higher degree of mutual understanding and so take most of the decisions in consultation with each other. Thus, the graduate and postgraduate women have greater percentage in moderate autonomy category i.e. $34 \%$.

The main focus of the present study is on the autonomy of the educated urban women and their attitude towards female foeticide. Thus, we select our sample on the basis of the above table. Women having graduate or higher level of education are taken to be educated women while women enjoying moderate to high autonomy level are considered to be autonomous women. Thus, the sample for the present study was selected accordingly: Total Women covered under initial survey - 1040; Number of Educated women (with graduate or above degree) - 344; Number of Autonomous women (having moderate to high autonomy) - 470; Sample selected for Present work (Women both educated and autonomous) - 182 .

The further analyses of attitude of educated autonomous women will be based on above sample which consists of a total of 182 women.

\section{Autonomous and educated urban women and their attitude towards female foeticide}

One of the greatest threats to our contemporary civilization is the menace of skewed sex ratio which is the result of widespread practice of aborting the female child even before birth i.e. female foeticide. Female foeticide is one of the most nefarious crimes on the earth and perhaps what is more detestable is that even the so-called educated and modern people are involved in this crime. The various reasons which give rise to son-preference and daughter discrimination and resultant female foeticide can be summed up as follows:

Problem of dowry for girls - Dowry normally means gifts given during the marriage to the son in-law or his parents either in cash or kind. This practice of giving dowry, which was meant to assist the newly-wed couple to start their new life together with ease, has now degenerated into a commercial transaction in which monetary considerations receive priority over the personal merits of the bride. There is no 
lower or upper limits of dowry. Depending upon the status of the family as well as the education, post and salary of the bridegroom it may range from few thousands to more than one Crore rupees. In addition to dowry demands in cash there are demands of costly household items like motorbikes, cars, television, refrigerators etc. Moreover, the dowry practice can deteriorate into a method of extortion of wealth from the brides to the groom's parents, leaving many daughters parents in debt. -"Raising a daughter is like watering someone else's field" is a common saying among many people. As such, often a girl child becomes an avoidable socioeconomic burden to the parents.

Sons carry family name - In India, society is rigidly patrilineal and strong son preference is an inherent feature of patrilineal society. The males are considered heir to property, thus, exacerbating the problem of female foeticide. There is great pressure on the young brides (especially in families already having many daughters) to beget a son and provide the family with an heir. It is often quoted that daughters are „Parayadhan“ (others property) i.e. they have to go away to their husbands home after their marriage, adopt husbands name and the children, too, carry their father's name. Thus, only the son can keep the family name running.

Perform the last rites - According to the traditional Indian Hindu view, only the sons are allowed to light the funeral pyre and perform the other funeral rites. Only then can the parents attain „moksha“ or „paith“. Also, the holy scriptures allow only the sons to perform the "pind-daan“ to the forefathers. According to one respondent "If this fact that only the son can give fire to the funeral pyre was not there then there would have been no difference between sons and daughters".

Give financial support in old age - The need for financial support in the old age was the reason considered to be the most important for son-preference, mostly by the widowed mothers or the poor respondents. The rate of employment or selfdependence is still very low among the Indian women who depend upon their husbands. For such women, the importance of son as an old age financial security against adversity is much greater than the men.

Provide protection in old age - The aged parents also need protection from the antisocial elements e.g. in case of attempt of usurpation of family property, theft etc. All this leads to a strong son-preference among the women. According the many respondents the mere presence of a son acts as a deterrent to these anti-social elements and provides a great psychological strength to the parents.

Not having sons causes family rejection - In many of the traditional families, the daughtersin-law are still mistreated if they do not beget a son. They are ill-treated, abused and insulted. The only means available to enhance her prestige and even security in her husbands home is through the sons she bears. Many of the young women, thus, wish to have at least one son, so as to escape this mental and emotional torture.

Having sons give social prestige - This view springs out of the traditional patrilineal mindset, when the status of a woman in her marital family suddenly increases after giving birth to a son. She, as the mother of the family heir, is given more respect and better treatment than the other women in the household.

Daughters don't remain along with them after marriage - The traditional Indian „Patrilocal residence“ marriage custom has made the girls a „Parayadhan“. After their marriage they have to leave their parents home for their marital home only to return during some festivals, holidays or short rare visits. Thus, the parents who 
have only daughters are left without any company in their old age, while having a son will bring them a daughter-inlaw and then in future grand children who will not let them feel lonely.

Problem of security for girls - It is now one of the most significant aspects for the mothers to be worried about their daughters. Increasing incidences of crime against women and girls, especially those sexual in nature like eve-teasing, child abuse and rape both by strangers and relatives are making the mothers more concerned and anxious about security of girl child. A daughters honor is considered to be a matter of utmost importance, the loss of which causes a great blow to the family prestige. As the incidences of rape by close relatives and family friends is also on rise, most mothers feel that girls are not safe anymore, thus, it is better to have less or no daughter at all.

All these above son-preference and daughter discriminating factors combined with Preference for small size family and easy availability of Pre-natal sex determination tests resulting in sex-selective abortions have worked in combination and resulted in the dangerously low child sex ratio in India.

Though while in open, most of the people seem to oppose female foeticide citing it to be a cruel practice, yet behind closed doors, it is still a widely prevalent method of getting rid of unwanted girl child. Such widespread practice of female foeticide also makes it clear that even the women are an aware participant in this heinous crime. Surprisingly, though most of the women do agree that this act is neither morally or legally right yet there are many women who seem to accept and even support this barbaric practice citing socio-economic reasons.

According to Banashri B. Savanoor (2009):

"These unscrupulous murders of female or girls are justified on two grounds. First, it reduces the population and second is that the poor parents will be saved from the expenses which they would have to incur in the marriage of their daughter if she had born."

Many women also justify this on the grounds of saving their marriage when pressurized by their in-laws. As already discussed, it was earlier thought that illiteracy and female subjugation is the main reason why women are unable to stand for their rights and against atrocities on themselves including female foeticide. This is also the reason for skewing sex-ratio. Therefore, increasing the education level and autonomy of women will play a major role in checking this falling sex ratio in our country. But, is it really enough just to focus on increasing literacy and autonomy? To assess the attitude of the selected women, who were both educated and autonomous, towards female foeticide, a question was posed during the sample survey that whether female foeticide is justified in any condition or not.

Their response has been as under: Among the Graduate women those who justifying female foeticide for any reason is quite high, i.e. $68 \%$ of highly autonomous and $70 \%$ of moderately autonomous while those who do not justify it in any condition are 32\% of highly autonomous and 30\% of moderately autonomous women.

While among the Post-Graduate women those who justifying female foeticide for any reason is comparatively much less than the graduate women, i.e. $45 \%$ of highly autonomous and $47 \%$ of moderately autonomous while those who do not 
justify it in any condition are significantly higher i.e. 53\% of moderately autonomous and $55 \%$ of highly autonomous women. But when the reasons for justification of female foeticide were analysed, certain surprising facts came up as shown by Table 2 .

The justification of female foeticide by the women having education up to graduation level (both moderately autonomous and highly autonomous) is mostly on the grounds of compulsion i.e. in case of being pressurized by either in-laws of husband. Figure 4 shows that $18 \%$ of moderately autonomous graduate women justify aborting their girl child if and when pressurized by their inlaws while 40$43 \%$ of these graduate women accept this when forced by their husbands. This shows that not greater percent of women having education till graduation do not wilfully justify aborting their girl child. There have been many instances when the women were disowned by their marital family just due to their inability to produce a male child. As such, these women who justify female foeticide mostly do so for the sake of saving their marriage by not displeasing her in-laws or husband.

On the other hand, the justification of female foeticide given by the women having higher education (post-graduation or above) is mostly wilful. It can be noticed from Figure 5 that none of these highly educated women justified aborting their girl child after succumbing to pressure by in-laws. Even in case of acceding to the demand of husband for undergoing abortion of female child, it is to maintain a cordial atmosphere at their homes. Only 22\% of the highly autonomous women and $37 \%$ of moderately autonomous post-graduate women showed submission to their husbands pressure in such cases.

It should also be noted that wilful justification of female foeticide i.e. in case of already having a daughter or more, is much greater in cases of these highly educated autonomous women. According to them, opting for aborting the unborn girl child is, in a way, similar to family planning where they can control not only the number of their children but also their sex-composition. Also, according to many of these women, raising girl child is very costly and marrying them off is even costlier as huge amount of dowry has to be paid for them. This along with the fact that daughters would not live with them after their marriage to support them in their old age. Considering all these facts, these women justify female foeticide as a pragmatic solution to these multiple problems.

Table 2. Reasons for justifying female foeticide by educated autonomous women

\begin{tabular}{lcccccc}
\hline $\begin{array}{l}\text { Education } \\
\text { level }\end{array}$ & $\begin{array}{c}\text { Level of } \\
\text { autonomy }\end{array}$ & $\begin{array}{c}\text { Justified } \\
\text { female } \\
\text { foeticide }\end{array}$ & $\begin{array}{c}\text { Too many } \\
\text { Daughters }\end{array}$ & $\begin{array}{c}\text { Pressure } \\
\text { of In- } \\
\text { Laws }\end{array}$ & $\begin{array}{c}\text { Pressure } \\
\text { of } \\
\text { Husband }\end{array}$ & $\begin{array}{c}\text { Other } \\
\text { reasons }\end{array}$ \\
\hline Moderate & 55 & $15(27)$ & $10(18)$ & $22(40)$ & $8(15)$ \\
$\begin{array}{c}\text { Post- } \\
\text { Graduate }\end{array}$ & Moderate & 19 & $8(42)$ & 0 & $7(37)$ & $4(21)$ \\
\hline
\end{tabular}

(Figures in bracket indicate percentage of total)

Source - Based on sample survey (2010-11) 


\section{Conclusion}

The study shows that the women are quite varied in nature when it comes to their son-preference and daughter-discriminating nature. In spite of increase in level of education and autonomy, there are quite a significant proportion of women who justify aborting their unborn female child. The reason for the son-preference for these women is not traditional / cultural in any sense i.e. for continuation of family name or for performing funeral rites; rather it is purely for economic motive. Their main reason for son- preference is that marriages in our system are based on dowry i.e. exorbitant dowry has to be paid for the marriage of their daughters. They lament that after meeting all the general requirements like education, clothing etc. of their daughters, they cannot afford to pay the heavy demands of dowry so it becomes necessary to keep the number of girl children in limits. In some cases it was also noted that among such women, having sons is considered to be a matter of prestige. Therefore, after having a girl they strongly desire for a male child. For this they are also ready for aborting their female child.

The purpose of this study was to highlight the fact that there are women who are both educated and autonomous but still prefer sons and shy away from daughters and that too, for either purely economic motive i.e. fear of giving dowry, sons being economic support in old age etc. or social prestige issue. Thus, the policy makers should be clear that like for different diseases, we require different medicines, similarly to treat the problem of Son preference/daughter discrimination by such women, a different approach is necessary. For example:

1. Promoting and highlighting the rising gender equality through ad-campaigns. Anti-dowry campaigns and giving boost to girl education and female employment is an effective method to nullify the negative mind set of girl as a burden.

2. For the economically motivated women, stringent anti-dowry laws and providing monetary incentives for girl-education may prove effective in curbing this problem.

3. In case of the women who succumb to social compulsions to save one's family (pressure of marital family), initiating an "anti-female feticide campaign" to create a social environment which looks down upon the people promoting female-feticide and supports women fighting for the assertion of their rights might prove to be a good idea.

Thus, the author concludes that simply increasing the female literacy and autonomy without bringing about the change in mind-set and strict implementation of laws is not enough to combat the problem of female foeticide. There is a strong need to bring about diversity in the approaches towards the method to check the rapidly declining sex-ratio keeping in mind the different behavioural attitude of the women towards Son-preference/Daughter-discrimination.

\section{References}

Banerjee, P 2006, The Acts and Facts of Women's Autonomy in India, in M Aymard (ed) Diogenes, vol. 53, no. 4, pp. 85-101, Sage publications, New Delhi.

Bisaria, A 2006, Female Foeticide: Socio-psychological problem in India, UPJSSR, New Delhi, vol. 1, no. 07, pp. 11-15. 
Caldwell, JC, Reddy, PH \& Caldwell, P 1982, The causes of demographic change in rural South India: A micro approach, Population and Development Review, vol. 8, no. 4, pp. 689-727.

Clark, S 2000, Son-preference and sex composition: Evidence from India, Demography, vol. 37, no. 1, pp. 95-108.

Govt. of India 2011, Census of India.

Divya, R \& Geeta, B 2013, An Insight into the Family Environment of Indian Women in Relation to Female Foeticide and Girl Child, Asian Journal of Humanities and Social Studies, vol. 1, no. 2.

Dweepika, K 2013, Role of Women in declining sex-ratio in Patna: A Geographical Analysis, Unpublished Ph.D thesis, Patna University, Patna.

Jejeebhoy, SJ 2002, Convergence and divergence in spouses perspective on Women's autonomy in rural India, Studies in Family planning, New Delhi, vol. 33, no. 4, pp. 299308.

Kishor, S 2000, Empowerment of women in Egypt and links to the survival and health of their infants, in HB Presser \& G Sen (eds), Women's Empowerment and Demographic Processes: Moving Beyond Cairo, Oxford University Press, New York.

Krishanji, N 2000, Trends in Sex Ratio, Economic and Political Weekly, vol. April, pp. 1-7.

Mason, KO 1984, The Status of Women: A Review of Its Relationships to Fertility and Mortality, The Rockefeller Foundation, New York.

Ministry of Health and Family welfare 2005, Annual report on implementation of the preConception and Pre-natal Techniques (PNDT) prohibition of sex selection Act, PNDT Division, GOI, New Delhi, viewed 20 September 2011,

www.pndt.gov.in/writereaddata/mainlinkfile/file22.pdf.

Jejeebhoy, SJ \& Sathar, ZA 2001, Women's Autonomy in India and Pakistan: The influence of Religion and Region, Population and Development Review, vol. 27, no. 4, pp. 687-712, New Delhi.

Patel, V 1988, Sex-Determination and Pre-Selection tests: Abuse of advanced technology, R Ghadially (ed), Sage Publications, New Delhi, pp. 178-185.

Savanoor, BB 2009, Female foeticide: Need to change the mindset of people, viewed 15 October 2011, www.legalserviceindia.com

Surender, SR \& Rama, NS 1997, Attitude towards Female Foeticide: Does it Influence the survival Status of Female Children?, IASSI Quaterly, vol. 16, no. 3 \& 4, pp. 106-114. 